\title{
Emergence of New Delhi Metallo-Beta-Lactamase (NDM) and Klebsiella pneumoniae Carbapenemase (KPC) Production by Escherichia coli and Klebsiella pneumoniae in Southern Vietnam and Appropriate Methods of Detection: A Cross-Sectional Study
}

\author{
Cuong Q. Hoang $\mathbb{D}^{1}$, Hai D. Nguyen ${ }^{1}$, Huy Q. Vü ${ }^{2}$, Anh T. Nguyen ${ }^{3}$, Binh T. Pham $\mathbb{D}^{2}$, \\ Trung L. Tran ${ }^{4}$, Hanh T. H. Nguyen ${ }^{2}$, Y. M. Dao ${ }^{5}$, Tuyet S. M. Nguyen ${ }^{6}$, Dung A. Nguyen ${ }^{6}$, \\ Hang T. T. Tran ${ }^{2}$, and Lan T. Phan ${ }^{1}$ \\ ${ }^{1}$ The Pasteur Institute, Ho Chi Minh City 700000, Vietnam \\ ${ }^{2}$ Department of Medical Laboratory Science, Faculty of Nursing and Medical Technology, University of Medicine and Pharmacy, \\ Ho Chi Minh City 700000, Vietnam \\ ${ }^{3}$ Molecular Biomedical Center for Diagnosis and Training, University Medical Center Branch No. 2, \\ Medical and Pharmacy University Hospital, Ho Chi Minh City 700000, Vietnam \\ ${ }^{4}$ College of Dentistry, Yonsei University, 50-1 Yonsei-ro, Seodaemun-gu, Seoul 03722, Republic of Korea \\ ${ }^{5}$ Department of Microbiology, Dong Nai General Hospital, Dong Nai Province 710000, Vietnam \\ ${ }^{6}$ Department of Microbiology, Gia Dinh People's Hospital, Ho Chi Minh City 700000, Vietnam
}

Correspondence should be addressed to Cuong Q. Hoang; cuonghqpasteur@gmail.com

Received 30 November 2018; Revised 7 March 2019; Accepted 31 March 2019; Published 23 April 2019

Academic Editor: Anjali Joshi

Copyright (C) 2019 Cuong Q. Hoang et al. This is an open access article distributed under the Creative Commons Attribution License, which permits unrestricted use, distribution, and reproduction in any medium, provided the original work is properly cited.

Carbapenemase-producing Enterobacteriaceae (CPE) are well known to cause many serious infections resulting in increasing mortality rate, treatment cost, and prolonged hospitalization. Among the widely recognized types of carbapenemases, New Delhi $\beta$-lactamase (NDM) and Klebsiella pneumoniae carbapenemase (KPC) are the most important enzymes. However, in Vietnam, there are only scattered reports of CPE due to the lack of simple and affordable methods that are suitable to laboratory conditions. This study aims to survey the characteristics of carbapenem-resistant E. coli and K. pneumoniae (CR-E/K) at two hospitals in Southern Vietnam and perform some simple methods to detect the two enzymes. A total of $100 \mathrm{CR}-\mathrm{E} / \mathrm{K}$ strains were collected from clinical isolates of Gia Dinh People's Hospital and Dong Nai General Hospital, Vietnam, from November 2017 to May 2018. The patient-related information was also included in the analysis. We conducted real-time polymerase chain reaction (PCR), Modified Hodge Test (MHT), and combined disk test (CDT) on all isolates. Carbapenemase-encoding genes were detected in 47 isolates (36 NDM, $10 \mathrm{KPC}$, and one isolate harboring both genes). The E. coli strain carrying simultaneously these two genes was the first case reported here. Most of isolates were collected from patients in ICU, Infectious Disease Department, and Department of Urologic Surgery. Urine and sputum were two common specimens. The true positive rate (sensitivity, TPR) and specificity (SPC) of the imipenem-EDTA (ethylen diamine tetra acetic acid) for NDM detection and the imipenem-PBA (phenylboronic acid) for KPC detection on E. coli were $93.8 \%, 97.1 \%$ and $66.7 \%, 95.7 \%$, respectively. Meanwhile, the imipenem-EDTA for NDM detection and the imipenem-PBA for KPC detection among K. pneumonia achieved 90.5\%, 100\% and 100\%, 92.9\% TPR and SPC, respectively. However, MHT showed low sensitivity and specificity. Our findings showed that CP-E/K were detected with high prevalence in the two hospitals. We suggest that CDT can be used as a low-priced and accurate method of detection. 


\section{Introduction}

Antibiotic resistance is a tremendous health problem. This includes the resistance to carbapenems which was considered as the last resort for Enterobacteriaceae infections [1]. In 2017, the World Health Organization published a list of superbugs including carbapenem-resistant Enterobacteriaceae. Carbapenemase production and ESBL/AmpC $\beta$ lactamase production coupled with porin loss or efflux pump were the common ways that Enterobacteriaceae become resistant to carbapenems [2]. However, the carbapenemase production was more dangerous than the others [2]. E. coli and $K$. pneumoniae are the most common pathogens in Enterobacteriaceae family. These carbapenemasae-producing bacteria were found in many countries, such as China [3], Parkistan [4], India [5], Turkey [6], Brazil [7], Mexico [8], Peru [9], and Greece [10]. Through this mechanism, New Delhi Metallo- $\beta$-lactamase-1 (NDM-1) was found in Asia with the highest frequency; Klebsiella pneumoniae carbapenemase (KPC) was the most popular enzyme causing carbapenem resistance, especially KPC-2 [1, 11, 12]. Furthermore, KPC-producing bacteria have spread all over the world, including Asia [11]. Some gray literature also reported about KPC-producing Enterobacteriaceae in Vietnam [1315]. In other important views, these two genes harboring bacteria were more dangerous and resistant to carbapenem with a higher level than bacteria that harbored other types of carbapenemase-encoding genes (including OXA48-like, another popular carbapenemase present in Enterobacteriaceae) [6,16-18]. For instance, these carbapenemaseproducing bacteria result in severe infections with high mortality rate; the infection caused by KPC-producing $K$. pnuemoniae was from $40 \%$ to $56 \%$ [16] and up to $88 \%$ for NDM-1 producing Enterobacteriaceae [6]. Carbapenem minimum inhibitory concentrations (MICs) for these two types of carbapeenemase producers in recent studies were higher than carbapenem MIC values against OXA- 48 type producers $[17,18]$.

In another aspect, these bacteria have spread rapidly through mobilisable genetic elements [19, 20], for example, plasmid IncX3 [21], IncA/C2 [22]; transposon Tn4401 [23], Tn125 [21], or class I Integron [24]. These elements also play important roles in the existence of multiple genes and transporting various multidrug-resistant genes between bacterial species.

In Vietnam, the prevalence of these CPE is increasingly being reported in the hospital and aquatic environment [2527]. Data about carbapenemase-producing E. coli and $K$. pneumoniae were reported notably in Southern and Northern Vietnam. Due to the lack of needed methods for screening and detection, there is an underestimation of CPE in other regions of Vietnam. The requirement for low-priced and efficient methods to screen or confirm carbapenemaseproducing bacteria in laboratories, which are likely to be suitable for low-resource settings in Vietnam, is urgent. Today, the combinations of meropenem and varbobactam or imipenem and relebactam are taken into consideration as an option to treat infections caused by KPC-producing organisms $[28,29]$. Therefore, it is vital to select an efficient method to detect and characterize these carbapenemaseproducing Enterobacteriaceae, particularly in Vietnam.

Among various methods, PCR, real-time PCR, and DNA sequencing are the gold standards for carbapenemaseencoding genes detection, but these methods have not been widely used in Vietnam due to the high cost. Phenotypic tests such as Modified Hodge Test and the combined disk test are suitable because of the lower cost. The combined disk test is based on the synergy between metallo- $\beta$-lactamases (MBLs) or KPC inhibitors (EDTA or PBA) and carbapenems. Many studies used these methods but none of them investigated $E$. coli and K. pneumoniae separately [30, 31]. The purpose of this study was to evaluate the characteristics of NDM/KPCproducing E. coli/K. pneumoniae at the hospitals in the South Vietnam and to assess some simple methods for detecting these bacteria in laboratory conditions.

\section{Materials and Methods}

2.1. Study Design and Sample Collection. The study was designed as a cross-sectional study, including all clinical isolates from November 2017 to May 2018. The study was conducted at the Molecular Biomedicine Laboratory in the Department of Medical Laboratory Science, University of Medicine and Pharmacy, Ho Chi Minh City. 100 clinical isolate strains (50 E. coli and $50 \mathrm{~K}$. pneumoniae) were collected from the Microbiology Department of Gia Dinh People's Hospital and Dong Nai General Hospital. All of them were nonsusceptible to one of the carbapenems (imipenem, meropenem, or ertapenem) detected by the automatic systems. Patient data such as age, sex, specimen types, and clinical wards were gathered to survey the characteristics of patients. Sample list and relevant information are supplied in Annex 1.

2.2. Bacterial Isolates. Fifty-nine isolates from Gia Dinh People's Hospital were identified and subjected to antimicrobial susceptibility testing by using the Vitek 2 system (bioMérieux Vitek Inc., Hazelwood, MO, USA). Furthermore, ID/AST of 41 isolates from Dong Nai General Hospital was performed by using BD Phoenix ${ }^{\mathrm{TM}}$ (USA). From those hospitals, a single colony obtained from pure culture was inoculated into BHI (Heart Infusion Broth, Himedia, India) broth, with $20 \%$ glycerol (Xilong medical, China), and stored at $20^{\circ} \mathrm{C}$, to reculture for extracting DNA for real-time PCR and performing phenotypic methods.

\subsection{Real-Time PCR}

2.3.1. DNA Extraction. Bacterial DNA was extracted by heat treatment. One colony form pure isolates incubated overnight on MacConkey agar (Merck KgaA, Darmstadt, Germany) was suspended in $200 \mu \mathrm{L}$ of Tris-EDTA pH 8.0. The suspension was heated at $95^{\circ} \mathrm{C}$ for 20 minutes, followed by centrifugation at 13,000 revolutions per minute for 10 minutes to collect $150 \mu \mathrm{L}$ supernatant, and stored at $-20^{\circ} \mathrm{C}$ for real-time PCR. DNA quality was evaluated using NanoDrop ${ }^{\text {TM }} 2000$ Spectrophotometer (ThemoFisher Scientific, Wilmington, 
Table 1: Primers and probes used in this study.

\begin{tabular}{|c|c|c|c|c|}
\hline Oligonucleotide & Nucleotide sequence, $5^{\prime}-3^{\prime}$ & Origin & Volume of reaction $(\mathrm{nM})$ & Reference \\
\hline \multicolumn{5}{|c|}{ Primers and probes for real-time PCR } \\
\hline NDM-F Primer & GAC CGC CCA GAT CCT CAA & IDT & 300 & \multirow{9}{*}[32]{} \\
\hline NDM-R Primer & CGC GAC CGG CAG GTT & IDT & 300 & \\
\hline NDM-probe & HEX-TG GAT CAA GCA GGA GAT-ZEN/IBFQ & IDT & 200 & \\
\hline KPC-F Primer & GGC CGC CGT GCA ATA C & IDT & 500 & \\
\hline KPC-R Primer & GCC GCC CAA CTC CTT CA & IDT & 500 & \\
\hline KPC- probe & 6FAM-TG ATA ACG CCG CCG CCA ATT TGT-ZEN/IBFQ & IDT & 200 & \\
\hline 16S rRNA-F Primer & TGG AGC ATG TGG TTT AAT TCG A & IDT & 200 & \\
\hline 16S rRNA-R Primer & TGC GGG ACT TAA CCC AAC A & IDT & 200 & \\
\hline 16S rRNA-probe & Cy5-CA CGA GCT GAC GAC AR*C CAT GCA-IBRQ & IDT & 100 & \\
\hline \multicolumn{5}{|c|}{ Primers for DNA sequencing } \\
\hline NDM-F-seq & AGT CGC TTC CAA CGG TTT & IDT & 300 & \multirow{4}{*}{ This study } \\
\hline NDM-R-seq & CAT TGG CAT AAG TCG CAA TCC & IDT & 300 & \\
\hline KPC-F-seq & GGT CAC CCA TCT CGG AAA & IDT & 500 & \\
\hline KPC-R-seq & GGG ATG GCG GAG TTC AG & IDT & 500 & \\
\hline
\end{tabular}

Delaware, USA) with the acceptable range for the ratio of absorbance at $260 \mathrm{~nm} / 280 \mathrm{~nm}$ from 1.6 to 1.8 .

2.3.2. Genotypic Detection of blaNDM, blaKPC, and $16 S$ $r R N A$. The genes were detected by real-time PCR using TaqMan probes for all samples and were confirmed by DNA sequencing of selected positive samples. The bacterial DNA was performed to screen for the presence of blaNDM and blaKPC. The reaction used bacterial $16 \mathrm{~S}$ rRNA gene as an internal control for DNA extraction and amplification process. The primers and probes used for blaNDM, blaKPC, and 16S rRNA were described by the Center of Disease Control and Prevention [32]. To carry out real-time PCR, $5 \mu \mathrm{L}$ DNA was added to a final volume of $20 \mu \mathrm{L}$ Master Mix, which included 1X PCR buffer, $4 \mathrm{mM} \mathrm{MgCl}, 0.2 \mathrm{mM}$ dNTPs, and 5 IU Taq DNA polymerase (Solgent Co., Ltd., South Korea). The concentration for each primers and probes is illustrated in Table 1. The negative control for PCR reaction is sterile DEPC-treated water. DNA from GD018, which is a clinical isolate that carries both blaNDM and blaKPC (confirmed by DNA sequencing), is used as a positive control.

The real-time PCR conditions were chosen as follows: Enzyme activation was achieved by primary heating step at $95^{\circ} \mathrm{C}$ for 15 minutes. This was followed by 40 cycles of $95^{\circ} \mathrm{C}$ for 15 seconds and $56^{\circ} \mathrm{C}$ for 20 seconds. Real-time PCR was run on CFX96 Touch $^{\text {TM }}$ Real-Time PCR Detection System (Bio-Rad, Hercules, California, USA). Fluorescence signal was detected after each cycle. Positive sample was determined when the automatically normalized fluorescence signal rises above the threshold limit value calculated in each run. A total of 40 cycles takes 70 minutes.

2.3.3. DNA Sequencing. DNA extracts from selected positive samples for blaNDM (GD013, GD002, and GD018) and blaKPC (GD011, GD16, and GD018) were sequenced using the sequencing primers. Initial PCR proceeded in the above-mentioned conditions, and PCR products were sent to
1-BASE (Singapore) for Sanger's sequencing. 16S rRNA genes from two samples GD013 and GD018 were also sequenced to confirm the validity of the internal control primers.

2.4. Modified Hodge Test (MHT). The MHT was carried out on all isolates, following the Clinical \& Laboratory Standards Institute (CLSI) guide on Mueller-Hinton agar (MHA-Becton Diskinson, US) using $10 \mu \mathrm{g}$ meropenem (MEM) disks (Nam Khoa Biotech, Vietnam) [33]. Klebsiella pneumoniae ATCC ${ }^{\circledR} \mathrm{BAA}-1705$ and Klebsiella pneumoniae ATCC ${ }^{\circledR}$ BAA-1706 were used as a positive control and a negative control, respectively.

2.5. Combined Disk Test (PBA/IPM-EDTA/IPM). Phenylboronic acid solution was prepared by dissolving $2 \mathrm{~g}$ phenylboronic acid (PBA) (Sigma-Aldrich, Steinheim, Germany) in $100 \mathrm{~mL}$ solution containing $50 \mathrm{~mL}$ distilled water and $50 \mathrm{~mL}$ Dimethyl Sulfoxide (Xilong medical, China). EDTA $0.25 \mathrm{M}$ solution prepared by mixing 18.61 g disodium ETDA. $2 \mathrm{H}_{2} \mathrm{O}$ in $200 \mathrm{~mL}$ of distilled water was adjusted to $\mathrm{pH} 8.0$ by using $\mathrm{NaOH}$. Both solutions were autoclaved at $121^{\circ} \mathrm{C}$ for 15 minutes. Either $20 \mu \mathrm{L}$ phenylboronic acid solution $(400 \mu \mathrm{g}$ PBA) or $10 \mu \mathrm{L}$ EDTA solution $(930 \mu \mathrm{g}$ EDTA) was added on a $10 \mu \mathrm{g}$ imipenem disk (IPM) to get a PBA/IPM or EDTA/IPM disk, respectively. These disks were used within 1 hour.

A bacterial suspension with McFarland Equivalence Turbidity Standard 0.5 was streaked on MHA plate using a swab. Three disks, IPM, EDTA/IPM, and PBA/IPM, were placed on the MHA plate with the distance from one disk to another being at least $24 \mathrm{~mm}$. Klebsiella pneumoniae ATCC ${ }^{\circledR} \mathrm{BAA}-1705$ and Klebsiella pneumoniae ATCC ${ }^{\circledR} \mathrm{BAA}-$ 1706 were used as a positive control and a negative control, respectively. An increase of $7 \mathrm{~mm}$ for EDTA/IPM or $5 \mathrm{~mm}$ for PBA/IPM in the diameter of the zone of inhibition compared to that of IPM was considered as a positive result for NDM or KPC production, respectively. 
TABLE 2: Distribution of diseases.

\begin{tabular}{|c|c|c|c|c|c|c|c|c|c|c|}
\hline \multicolumn{11}{|c|}{ Disease } \\
\hline Hospital & & Pneumonia & UTI & $\begin{array}{l}\text { Wound } \\
\text { Infection }\end{array}$ & $\begin{array}{c}\text { Abnormal } \\
\text { Infection }\end{array}$ & Bacteremia & Fever & $\begin{array}{l}\text { Surgical } \\
\text { Wound } \\
\text { Infection }\end{array}$ & Other & Total \\
\hline \multirow{2}{*}{$\begin{array}{l}\text { GD } \\
(\mathrm{N}=59)\end{array}$} & $\mathrm{E}$ & 2 & 14 & 5 & 0 & 5 & 2 & 0 & 1 & 29 \\
\hline & $\mathrm{K}$ & 13 & 9 & 2 & 1 & 2 & 2 & 1 & 0 & 30 \\
\hline \multirow{2}{*}{$\begin{array}{l}\mathrm{DN} \\
(\mathrm{N}=41)\end{array}$} & $\mathrm{E}$ & 3 & 10 & 3 & 0 & 0 & 1 & 2 & 2 & 21 \\
\hline & $\mathrm{K}$ & 11 & 2 & 3 & 0 & 0 & 0 & 2 & 2 & 20 \\
\hline Total & & 29 & 35 & 13 & 1 & 7 & 5 & 5 & 5 & 100 \\
\hline
\end{tabular}

*E: E. coli, K: K. pneumoniae, GD: Gia Dinh People's Hospital, DN: Dong Nai General Hospital, UTI: Urinary Tract Infection.

2.6. Statistical Analysis. Data were entered using Excel 2010, and all statistical analyses were carried out using SPSS version 22.0 (IBM Corp. 2013). We determined characteristics of patients carrying carbapenemase-producing bacteria with 95\% confidence interval (CI); odds ratio (OR) was calculated. Chi-square and Fisher exact tests were used for categorical variables. Independent sample t-test was used for comparing the mean ages of the two groups.

Real-time PCR was considered as a gold standard method. Sensitivity and specificity, negative predictive values (NPV), and positive predictive values (PPV) were also calculated. These values of MHT and CDT were compared using the nonparametric McNemar's test. $P$-values less than 0.05 were considered as statistical significance.

\section{Results and Discussion}

\subsection{Results}

3.1.1. Characteristics of Carbapenemase-Producing E. coli and K. pneumoniae at 2 Hospitals in the Southern Vietnam. In general, of 100 strains from clinical samples (50 isolates of E. coli and 50 isolates of $K$. pneumoniae), 47 isolates were positive by real-time PCR. In those positive strains, 36 carried blaNDM, 10 carried blaKPC, and one carried both genes. $58.3 \%$ (21/36) strains carrying blaNDM and $80 \%(8 / 10)$ strains carrying blaKPC were K. pneumoniae. The one carried both genes was E. coli. CRE were mainly isolated from sputum (37\%) and urine (31\%). Samples were collected from 13 different sites of ICU (14\%), Department of Urologic Surgery (14\%), Infectious Disease Department (17\%), Geriatrics Department (9\%), Respiratory Department (9\%), and some other departments $(37 \%)$. The majority of the study participants were male (55\%). The average age was 66.9 (95\% CI: 63.6-70.9), the youngest patient was 23 , and the oldest one was 94 . The proportion of people aged 60 years and older was $69 \%$; the odd ratio of patients in the elder group infected by E. coli or K. pneumoniae having carbapenemaseencoding genes was 3.18 (95\% CI: 1.28-7.89) compared to the other group. Furthermore, in Dong Nai General Hospital, the number of the elders infected by NDM/KPC producers was significantly higher than that of the younger ones $(\mathrm{p}=0.001)$. The prevalence of pneumonia was $29.0 \%$, the odd of CP$\mathrm{E} / \mathrm{K}$ infected patients with pneumonia was 2.32 (95\% CI:
0.93-5.78) compared to $\mathrm{CP}-\mathrm{E} / \mathrm{K}$ infected patients without pneumonia; the odd of elders with pneumonia was $9.32(95 \%$ CI: 2.05-42.29) compared to the younger ones.

Moreover, data from our study indicated that the rate of $\mathrm{CPE}$ is different between the two hospitals. NDM-producing organisms were the major pathogens in Gia Dinh People's Hospital (45.8\%). The prevalence of bacteria carrying blaNDM and blaKPC seems to be the same in Dong Nai General Hospital (22\% for blaNDM versus $19.5 \%$ for blaKPC) (Figure 1). Other characteristics of CRE infected patients were described in Figures 1 and 2, Tables 2 and 3.

3.1.2. Molecular Detection. The conformity of three methods was illustrated in Table 3.

3.1.3. The Modified Hodge Test (MHT). All isolates were evaluated by using the MHT and real-time PCR. This method showed low sensitivity and specificity compared to real-time PCR, especially in K. pneumoniae. 38\% (23/53) of strains were positive with the MHT whereas the real-time PCR results were negative. 8/47 strains were real-time PCR positive but negative for the MHT, and 7 of those 8 strains carried blaNDM. The sensitivity and specificity for $E$. coli and $K$. pneumoniae were $72.2 \%, 68.8 \%$ and $89.1 \%, 38.1 \%$, respectively. Moreover, the PPV and NPV for E. coli and K. pneumoniae were $56.5 \%, 81.5 \%$ and $66.7 \%, 72.7 \%$, respectively.

3.1.4. Combined Disk Test. In the same way, all isolates were tested using combined disk test (using EDTA and PBA).

3.2. Discussion. In our study, the prevalence of NDM and KPC-producing bacteria in both hospitals is high. Furthermore, the figures of NDM and KPC-producing E/K among infected patients were different between the two hospitals, which depend on areas and ages of patients (Figure 2). Probably, the high rate of integron and gene cassette carrying E. coli at Gia Dinh People's Hospital (45/65 strains carrying intergron gene and 32 of these 45 intergron harboring strains carrying gene cassette) [34] led to coharboring of the two genes in E. coli strain. In particular, this is the first report of the presence of $E$. coli strain coharboring both genes in Vietnam.

The average age of patients and the proportion of elder group at Gia Dinh People's Hospital were higher than these 
TABLE 3: Particular characteristics of patients at 2 hospitals in this study.

\begin{tabular}{|c|c|c|c|}
\hline Characters & $\begin{array}{l}\text { Gia Dinh People's Hospital } \\
\qquad(\mathrm{n}=59)\end{array}$ & $\begin{array}{l}\text { Dong Nai General Hospital } \\
\qquad(\mathrm{n}=41)\end{array}$ & $P$-value \\
\hline Average age $(95 \% \mathrm{CI})$ & $71.5(67.4-75.2)$ & $60.4(52.2-66)$ & 0.003 \\
\hline Range & $36-94$ & $23-89$ & \\
\hline Elder (\%) & 76.3 & 58.5 & 0.079 \\
\hline Positive rate (\%) & 50.8 & 41.5 & 0.545 \\
\hline Pneumonia rate $(\%)$ & 25.4 & 34.1 & \\
\hline $\begin{array}{l}\text { Odd of Outcome }(\mathrm{Pos} / \mathrm{Neg}) \\
\text { between Pneumonia and } \\
\text { the other }\end{array}$ & 0.79 & 7.14 & \\
\hline $\begin{array}{l}\text { Odd of Pneumonia } \\
\text { (Elder/Younger) }\end{array}$ & 5.88 & 18.91 & \\
\hline $\begin{array}{l}\text { Odd of Outcome } \\
\text { (Positive/Negative) in Elder } \\
\text { group/ the other. }\end{array}$ & 1.045 & 15 & \\
\hline Therapy departments (\%) & $\begin{array}{c}\text { ICU (20.3), } \\
\text { Geriatrics (15.3), } \\
\text { Department of Urologic } \\
\text { surgery (10.2), Respiratory } \\
\text { Department (8.5), and } \\
\text { other departments (45.7) }\end{array}$ & $\begin{array}{l}\text { Infectious Disease } \\
\text { Department (41.4) } \\
\text { Department of surgery } \\
\text { (19.5), Respiratory } \\
\text { Department (9.8), ICU } \\
\text { (4.9), and other } \\
\text { departments (24.4) }\end{array}$ & \\
\hline K. pneumoniae (\%) & $\underline{50.8}$ & 48.8 & \\
\hline
\end{tabular}

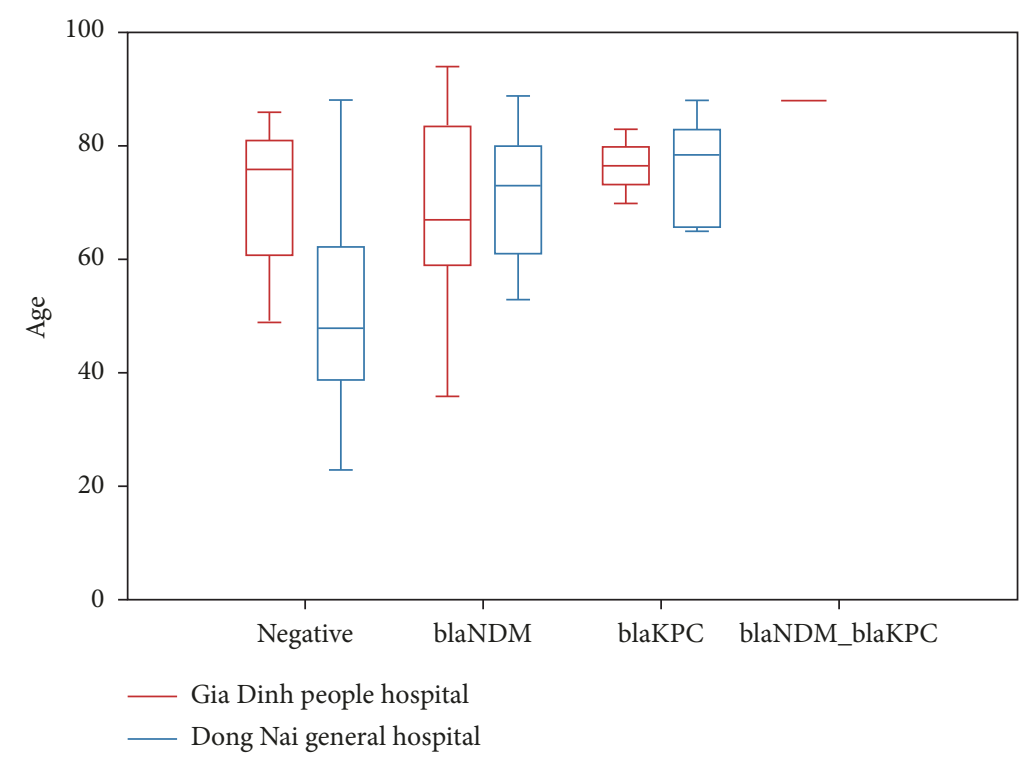

FIGURE 1: Different distribution of patients' age following genotype at 2 hospitals.

figures for Dong Nai General Hospital. In Dong Nai General Hospital, people infected by non-NDM/KPC-producing bacteria were young, most of whom were the group in the range from 40 to 60 (Figure 1); these young people could be infected with ESBL/AmpC producing E. coli/K. pneumoniae. Another hypothesis might be that the isolates from these patients could carry other carbapenemase-encoding genes, such as blaOXA-48-like, but these mechanisms cause a lower level of resistance $[2,17,18]$. These features could play an important role in the difference of the odd of positive and negative outcome of the elder group between these 2 hospitals. The elders who suffered from pneumonia and infection with the two types of carbapenemase producers were more than the younger ones, especially in Dong Nai General Hospital. The reason for the difference between these two hospitals was still unclear. It could be explained that Gia Dinh People's Hospital was established for a long time; the severity of illness was quite different compared with Dong Nai General Hospital. 
TABLE 4: The agreement of bacteria isolation, real-time PCR, and DNA sequencing results.

\begin{tabular}{lccc}
\hline Strains ID & Isolation & Real-time PCR & DNA sequencing \\
\hline GD013 & K. pneumonia & blaNDM, 16s rRNA & blaNDM, K. pneumoniae \\
GD002 & E. coli & blaNDM & blaNDM \\
GD018 & E. coli & blaNDM, blaKPC, 16S rRNA & blaNDM, blaKPC, E. coli \\
GD011 & K. pneumoniae & blaKPC & blaKPC \\
GD016 & K. pneumoniae & blaKPC & blaKPC \\
DN011 & K. pneumoniae & blaKPC & blaKPC \\
\hline
\end{tabular}

TABle 5: Combined disk test results in E. coli and K. pneumonia.

\begin{tabular}{|c|c|c|c|c|c|c|c|c|c|}
\hline \multirow{2}{*}{\multicolumn{2}{|c|}{$\begin{array}{c}\text { Combined disk test } \\
\text { Species }\end{array}$}} & & \multicolumn{2}{|c|}{ Real-time PCR } & \multirow{2}{*}{$\begin{array}{c}\text { TPR }(\%) \\
95 \%\end{array}$} & \multirow{2}{*}{$\begin{array}{l}\text { SPC } \\
(\%)\end{array}$} & \multirow{2}{*}{$\begin{array}{r}\text { PPV } \\
(\%)\end{array}$} & \multirow{2}{*}{$\begin{array}{r}\text { NPV } \\
(\%)\end{array}$} & \multirow{2}{*}{$\begin{array}{c}\text { Accuracy } \\
(\%)\end{array}$} \\
\hline & & & Pos & $\mathrm{Ne}$ & & & & & \\
\hline \multirow{4}{*}{$\begin{array}{l}\text { NDM } \\
\text { detection }\end{array}$} & \multirow{2}{*}{$\begin{array}{l}\text { E. coli } \\
(\mathrm{n}=50)\end{array}$} & Pos & 15 & 1 & \multirow{2}{*}{93.8} & \multirow{2}{*}{97.1} & \multirow{2}{*}{93.8} & \multirow{2}{*}{97.1} & \multirow{2}{*}{96.0} \\
\hline & & $\mathrm{Neg}$ & 1 & 33 & & & & & \\
\hline & \multirow{2}{*}{$\begin{array}{c}\text { K. pneumoniae } \\
(\mathrm{n}=50)\end{array}$} & Pos & 19 & 0 & \multirow{2}{*}{90.5} & \multirow{2}{*}{100} & \multirow{2}{*}{100} & \multirow{2}{*}{93.6} & \multirow{2}{*}{96} \\
\hline & & Neg & 2 & 29 & & & & & \\
\hline \multirow{4}{*}{$\begin{array}{l}\text { KPC } \\
\text { detection }\end{array}$} & E. coli & Pos & 2 & 2 & \multirow{2}{*}{66.7} & \multirow{2}{*}{95.7} & \multirow{2}{*}{50} & \multirow{2}{*}{97.8} & \multirow{2}{*}{94.0} \\
\hline & $(\mathrm{n}=50)$ & Neg & 1 & 45 & & & & & \\
\hline & \multirow{2}{*}{$\begin{array}{c}\text { K. pneumoniae } \\
(\mathrm{n}=50)\end{array}$} & Pos & 8 & 3 & \multirow{2}{*}{100} & \multirow{2}{*}{92.9} & \multirow{2}{*}{72.7} & \multirow{2}{*}{100} & \multirow{2}{*}{94} \\
\hline & & $\mathrm{Neg}$ & 0 & 39 & & & & & \\
\hline
\end{tabular}

* Pos: positive, Neg: negative.

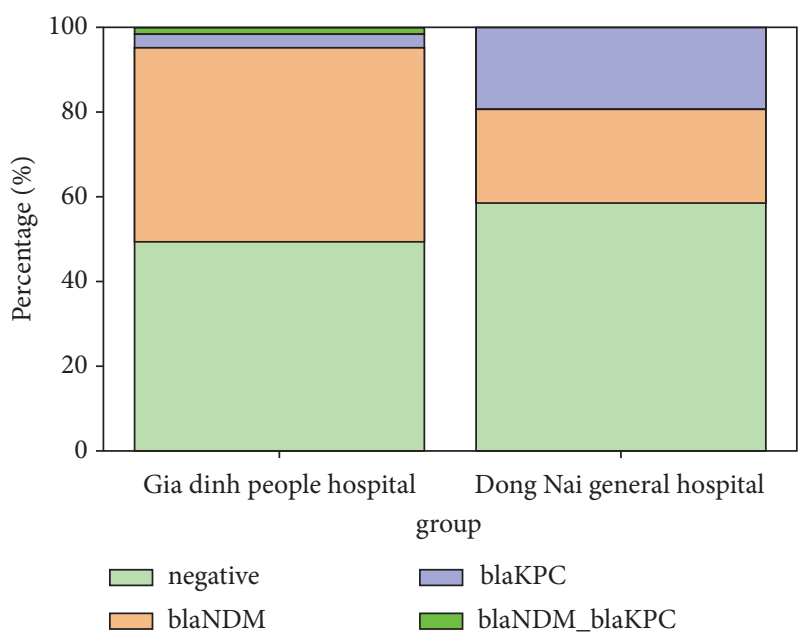

FIGURE 2: Different distribution of prevalence of CPE at 2 hospitals.

Regarding the methods, real-time PCR is an accurate and rapid method to detect the presence of carbapenemaseencoding genes. However, the cost associated with the method is one of the major disadvantages that limits its use in common laboratories in Vietnam. Among various phenotypic methods, MHT recommended in CLSI 2017 is a simple method [33]. In this study, SPC of MHT is low (23/53 K. pneumoniae strains were positive, but negative for the realtime PCR). The possible reason for this is that other types of carbapenemase may present in these bacteria. However, it could be explained that AmpC, ESBLs, or strict requirements of MHT process at each step may cause false positive results [35]. Besides, this method shows low sensitivity to NDMproducing Enterobacteriaceae (7/8 strains were found to have a false-negative result) $[36,37]$. In our study, the MHT results for $K$. pneumoniae are consistent with findings in recent studies conducted by Dariush Shokri et al. [38] and Rangneka $\mathrm{R}$ aSeeM et al. [39]. This may be the reason why the CLSI 2018 standard excluded MHT in the guideline [40].

In contrast, CDT has been shown to be highly effective. The results of NDM detection by EDTA disk test for K. pneumoniae (Table 4) were in accordance with findings obtained by Paradimitriou-Oliveris et al. [30]. However, it was in contrast to findings reported by Dariush Shokri et al. [38]. This could be explained by the fact that Shokri carried out his study including not only K. pneumoniae, but also $A$. baumanii and $P$. aeruginosa. The high rate of blaVIM in $P$. aeruginosa may be the reason for false-negative results. A study conducted by Ting-ting Qu et al. in 2009 showed that CDT also detected other types of carbapenemase including Verona integron-borne metallo- $\beta$-lactamase (VIM), which was the most widespread metallo- $\beta$-lactamase in $P$. aeruginosa [41, 42]. Our results for KPC detection using PBA disk test $K$. pneumoniae (Table 4) were in accordance with findings obtained by Athanasios Tsakris et al. (using PBA$400 \mu \mathrm{g}$ ) [31] and Julio Zúñiga et al. (using 300 $\mu$ g APBA) [43]. The efficiency of PBA disk test in E. coli was low, particularly in sensitivity and PPV because of the sample size of KPCproducing E. coli, only 3 strains with one of them being a false negative. The results in Tables 5 and 6 illustrated the significantly higher specificity of combined disk test compared with MHT. 
TABLE 6: Comparison between the MHT and combined disk test.

\begin{tabular}{llcccccc}
\hline \multirow{2}{*}{ Bacteria } & \multirow{2}{*}{ Index } & \multicolumn{3}{c}{ NDM detection } & \multicolumn{3}{c}{ KPC detection } \\
& & MHT & EDTA & McNemar* & MHT & Boronic & McNemar* \\
\hline \multirow{2}{*}{ E. coli $(\mathrm{n}=50)$} & TPR (\%) & 72.2 & 93.8 & $\mathrm{p}=0.25$ & 72.2 & 66.7 & $\mathrm{p}=1.00$ \\
& SPC (\%) & 68.8 & 97.1 & $\mathrm{p}=0.006$ & 68.8 & 95.7 & $\mathrm{p}<0.001$ \\
\hline \multirow{2}{*}{ K. pneumoniae ( $=50)$} & TPR (\%) & 89.7 & 90.5 & $\mathrm{p}=1.00$ & 89.7 & 100 & $\mathrm{NC}$ \\
& SPC (\%) & 38.1 & 100 & $\mathrm{p}<0.001$ & 38.1 & 92.9 & $\mathrm{p}<0.001$ \\
\hline
\end{tabular}

* means nonparametric McNemar test.

\section{Conclusions}

The prevalence of CP-E/K in Vietnam is high. The lack of suitable methods to detect and differentiate these bacterial infections has been the main obstacle for clinicians to choosing an appropriate treatment. During this study, we recognized that CDT is reasonable and simple to detect the presence of these important enzymes. These features make it highly applicable to all clinical laboratories in Vietnam.

\section{Data Availability}

The data used to support the findings of this study are available from the corresponding author upon request.

\section{Additional Points}

Limitation. In our study, other genes such an OXA-48-like, ESBL, and AmpC $\beta$-lactamase were not included, so this could affect our study results. The only $10 \mathrm{KPC}$-producing organisms in this study may have effects on the results of PBA disk test. A lack of genotypic method to identify E.coli and $K$. pneumoniae was also important.

\section{Conflicts of Interest}

The authors declare that there are no conflicts of interest regarding the publication of this paper.

\section{Acknowledgments}

The authors are grateful to Gia Dinh People's Hospital (HCMC) and Dong Nai General Hospital for kindly providing the clinical isolates and also to the staff of Pasteur Institute in Ho Chi Minh City for the comments and suggestions. We would also like to thank Dr. Vu Quang Huy, the Head of the Department of Medical Laboratory Science, University of Medicine and Pharmacy, Ho Chi Minh City, for facilitating the study and thank Pham Thai Binh (Nam Khoa Biotech), Bui The Trung (Children's Hospital no. 2, HCMC), and Nguyen Thi Phuong Thao (Dong Nai Medical College) for providing the ATCC strains of bacteria and some reagents for this study.

\section{Supplementary Materials}

List of related information of patients and testing results were detailed in Annex 1. Data analysis results, testing images, reference, and full-text of gray literature, were described in Annexes 2, 3, 4, 5, respectively. (Supplementary Materials)

\section{References}

[1] A. U. Khan, L. Maryam, and R. Zarrilli, "Structure, Genetics and Worldwide Spread of New Delhi Metallo- $\beta$-lactamase (NDM): a threat to public health," BMC Microbiology, vol. 17, no. 1, 2017.

[2] X. Jia, W. Dai, W. Ma et al., "Corrigendum: carbapenemresistant e. cloacae in southwest china: molecular analysis of resistance and risk factors for infections caused by ndm-1producers," Frontiers in Microbiology, vol. 9, 2018.

[3] J. Wang, X. Yao, J. Luo, L. Lv, Z. Zeng, and J.-H. Liu, "Emergence of Escherichia coli coproducing NDM-1 and KPC-2 carbapenemases from a retail vegetable, China," Journal of Antimicrobial Chemotherapy, vol. 73, no. 1, pp. 252-254, 2018.

[4] K. M. Day, M. Salman, B. Kazi et al., "Prevalence of NDM-1 carbapenemase in patients with diarrhoea in Pakistan and evaluation of two chromogenic culture media," Journal of Applied Microbiology, vol. 114, no. 6, pp. 1810-1816, 2013.

[5] S. Eshetie, C. Unakal, A. Gelaw, B. Ayelign, M. Endris, and F. Moges, "Multidrug resistant and carbapenemase producing Enterobacteriaceae among patients with urinary tract infection at referral Hospital, Northwest Ethiopia," Antimicrobial Resistance and Infection Control, vol. 4, no. 1, article no. 12, 2015.

[6] O. Karabay, M. Altindis, M. Koroglu, O. Karatuna, Ö. A. Aydemir, and A. F. Erdem, "The carbapenem-resistant Enterobacteriaceae threat is growing: NDM-1 epidemic at a training hospital in Turkey," Annals of Clinical Microbiology and Antimicrobials, vol. 15, no. 1, 2016.

[7] I. Rossi Gonçalves, M. L. Ferreira, B. F. Araujo et al., "Outbreaks of colistin-resistant and colistin-susceptible KPC-producing Klebsiella pneumoniae in a Brazilian intensive care unit," Journal of Hospital Infection, vol. 94, no. 4, pp. 322-329, 2016.

[8] P. Torres-González, M. Bobadilla-del Valle, E. Tovar-Calderón et al., "Outbreak Caused by Enterobacteriaceae Harboring NDM-1 Metallo- $\beta$-Lactamase Carried in an IncFII Plasmid in a Tertiary Care Hospital in Mexico City," Antimicrobial Agents and Chemotherapy, vol. 59, no. 11, pp. 7080-7083, 2015.

[9] J. Tamariz, C. Llanos, C. Seas et al., "Draft genome sequence of the first New Delhi metallo- $\beta$-lactamase (NDM-1)-producing Escherichia coli strain isolated in Peru," Genome Announcements, vol. 6, no. 13, 2018.

[10] H. C. Maltezou, P. Giakkoupi, A. Maragos et al., "Outbreak of infections due to KPC-2-producing Klebsiella pneumoniae in a hospital in Crete (Greece)," Infection, vol. 58, no. 3, pp. 213-219, 2009.

[11] L. Dortet, G. Cuzon, V. Ponties, and P. Nordmann, "Trends in carbapenemase-producing Enterobacteriaceae, France, 2012 to 2014," Eurosurveillance, vol. 22, no. 6, 2017. 
[12] C.-R. Lee, J. H. Lee, K. S. Park, Y. B. Kim, B. C. Jeong, and S. H. Lee, "Global dissemination of carbapenemase-producing Klebsiella pneumoniae: Epidemiology, genetic context, treatment options, and detection methods," Frontiers in Microbiology, vol. 7, article no. 895, 2016.

[13] T. N. Phuong, Klebsiella pneumoniae carbapenemase producing Klebsiella pneumoniae molecular genetic characteristics University of Science, Vietnam National University Ho Chi Minh City, 2016.

[14] P. D. Thai, T. D. Linh, N. H. Thu, T. H. Hoang, T. H. Son, and T. T. V. Phuong, "Apply Southern-Blotting assay to detect KPCplasmid of enterobacteriaceae strains from clinical isolates from hospitals in Hanoi," Vietnam . Vietnam Journal of Preventive Medicine, vol. 27, no. 3, 2017.

[15] N. H. Thu, T. D. Linh, N. T. T. Mai, T. V. Phuong, N. H. L. Yen, and T. N. Duong, "Molecular epidemiology of Klebsiella pneumoniae carbapenemase - 2 producing Klebsiella pneumoniae isolated from Saintpaul Hospital," Vietnam Journal of Preventive Medicine, vol. 26, no. 8, 2016.

[16] J. A. Ramos-Castañeda, A. Ruano-Ravina, R. Barbosa-Lorenzo et al., "Mortality due to KPC carbapenemase-producing Klebsiella pneumoniae infections: Systematic review and metaanalysis: Mortality due to KPC Klebsiella pneumoniae infections," Infection, vol. 76, no. 5, pp. 438-448, 2018.

[17] V. Studentova, C. C. Papagiannitsis, R. Izdebski et al., "Detection of OXA-48-type carbapenemase-producing Enterobacteriaceae in diagnostic laboratories can be enhanced by addition of bicarbonates to cultivation media or reaction buffers," Folia Microbiologica, vol. 60, no. 2, pp. 119-129, 2015.

[18] R. Fattouh, N. Tijet, A. McGeer, S. M. Poutanen, R. G. Melano, and S. N. Patel, "What is the appropriate meropenem MIC for screening of carbapenemase-producing Enterobacteriaceae in low-prevalence settings?" Antimicrobial Agents and Chemotherapy, vol. 60, no. 3, pp. 1556-1559, 2016.

[19] A. Iyer, E. Barbour, E. Azhar et al., "Transposable elements in Escherichia coli antimicrobial resistance," Advances in Bioscience and Biotechnology, vol. 04, no. 03, pp. 415-423, 2013.

[20] P. Nordmann, T. Naas, and L. Poirel, "Global spread of carbapenemase producing Enterobacteriaceae," Emerging Infectious Diseases, vol. 17, no. 10, pp. 1791-1798, 2011.

[21] J. Feng, Y. Qiu, Z. Yin et al., "Coexistence of a novel KPC2-encoding MDR plasmid and an NDM-1-encoding pNDMHN380-like plasmid in a clinical isolate of Citrobacter freundii," Journal of Antimicrobial Chemotherapy, vol. 70, no. 11, pp. 29872991, 2015.

[22] T. Bosch, S. P. M. Lutgens, M. H. A. Hermans et al., "Outbreak of NDM-1-producing klebsiella pneumoniae in a Dutch hospital, with interspecies transfer of the resistance plasmid and unexpected occurrence in unrelated health care centers," Journal of Clinical Microbiology, vol. 55, no. 8, pp. 2380-2390, 2017.

[23] S. Navon-Venezia, K. Kondratyeva, and A. Carattoli, "Klebsiella pneumoniae: A major worldwide source and shuttle for antibiotic resistance," FEMS Microbiology Reviews, vol. 41, no. 3, pp. 252-275, 2017.

[24] S. Datta, S. Mitra, P. Chattopadhyay, T. Som, S. Mukherjee, and S. Basu, "Spread and exchange of bla NDM-1 in hospitalized neonates: role of mobilizable genetic elements," European Journal of Clinical Microbiology \& Infectious Diseases, vol. 36, no. 2, pp. 255-265, 2017.

[25] T. Tada, M. Tsuchiya, K. Shimada et al., "Dissemination of Carbapenem-resistant Klebsiella pneumoniae clinical isolates with various combinations of Carbapenemases (KPC-2, NDM1, NDM-4, and OXA-48) and 16S rRNA Methylases (RmtB and RmtC) in Vietnam," BMC Infectious Diseases, vol. 17, no. 1, p. 467, 2017.

[26] R. Isozumi, K. Yoshimatsu, T. Yamashiro et al., "BlaNDM-1positive Klebsiella pneumoniae from environment, Vietnam," Emerging Infectious Diseases, vol. 18, no. 8, pp. 1383-1385, 2012.

[27] T. H. Hoang, H. Wertheim, N. B. Minh et al., "Carbapenemresistant Escherichia coli and Klebsiella pneumoniae strains containing new delhi metallo-beta-lactamase isolated from two patients in Vietnam," Journal of Clinical Microbiology, vol. 51, no. 1, pp. 373-374, 2013.

[28] G. G. Zhanel, C. K. Lawrence, H. Adam et al., "Correction to: Imipenem-Relebactam and Meropenem-Vaborbactam: Two Novel Carbapenem- $\beta$-Lactamase Inhibitor Combinations," Drugs, vol. 78, no. 7, p. 787, 2018.

[29] M. P-WK, D. Bm, J. A Tm, R. Bc, A. Bs et al., "Relebactam is a Potent Inhibitor of the KPC-2 beta-Lactamase and Restores the Susceptibility of Imipenem Against KPC-Producing Enterobacteriaceae," Antimicrobial Agents and Chemotherapy, 2018.

[30] M. Christofidou, M. Papadimitriou-Olivgeris, E. D. Anastassiou et al., "Performance of four different agar plate methods for rectal swabs, synergy disk tests and metallo- $\beta$-lactamase Etest for clinical isolates in detecting carbapenemase-producing Klebsiella pneumoniae," Journal of Medical Microbiology, vol. 65, no. 9, pp. 954-961, 2016.

[31] A. Tsakris, I. Kristo, A. Poulou et al., "Evaluation of boronic acid disk tests for differentiating KPC-possessing Klebsiella pneumoniae isolates in the clinical laboratory," Journal of Clinical Microbiology, vol. 47, no. 2, pp. 362-367, 2009.

[32] Control CfD Prevention, "Multiplex real-time PCR detection of Klebsiella pneumoniae carbapenemase (KPC) and New Delhi metallo- $\beta$-lactamase (NDM-1) genes," Atlanta, vol. 500, no. 6-7, 2011.

[33] Institute CLS, "Performance standards for antimicrobial susceptibility testing," The Modified Hodge Test for Suspected Carbapenemase Production in Enterobacteriaceae: Clinical and Laboratory Standards Institute, pp. 108-113, 2017.

[34] V. Bich, D. A. Dung, B. N. A. Pha, and N. S. M. Tuyet, "Antibiotic resistance of escherichia coli in gia dinh people's hospital," Ho Chi Minh medical Journal, vol. 13, no. 6, pp. 253-257, 2009.

[35] S. S. Jeremiah, V. Balaji, S. Anandan, and R. D. Sahni, "A possible alternative to the error prone modified Hodge test to correctly identify the carbapenemase producing Gram-negative bacteria," Indian Journal of Medical Microbiology, vol. 32, no. 4, pp. 414-418, 2014.

[36] H.-K. Kim, J. S. Park, H. Sung, and M.-N. Kim, "Further modification of the modified hodge test for detecting metallo$\beta$-lactamase-producing carbapenem-resistant Enterobacteriaceae," Annals of Laboratory Medicine, vol. 35, no. 3, pp. 298305, 2015.

[37] B. A. Sultan, E. Khan, F. Hussain, A. Nasir, and S. Irfan, "Effectiveness of Modified Hodge Test to detect NDM-1 Carbapenemases: An experience from Pakistan," Journal of the Pakistan Medical Association, vol. 63, no. 8, pp. 955-960, 2013.

[38] D. Shokri, M. R. Khorasgani, S. M. Fatemi, and A. SoleimaniDelfan, "Resistotyping, phenotyping and genotyping of new delhi metallo- $\beta$-lactamase (NDM) among gram-negative bacilli from Iranian patients," Journal of Medical Microbiology, vol. 66, no. 4, pp. 402-411, 2017.

[39] R. Aseem, "Approach to carbapenemase detection in klebsiella pneumoniae in routine diagnostic laboratories," Journal of 
Clinical and Diagnostic Research, vol. 10, no. 12, pp. DC24-DC7, 2016.

[40] Institute CLS, "Performance standards for antimicrobial susceptibility testing," Modified Carbapenem Inactivation Methods for Suspected Carbapenemase Production in Enterobacteriaceae and $P$ aeruginosa, pp. 112-122, 2018.

[41] T. Qu, J. Zhang, J. Wang et al., "Evaluation of phenotypic tests for detection of metallo- $\beta$-lactamase-producing pseudomonas aeruginosa strains in china," Journal of Clinical Microbiology, vol. 47, no. 4, pp. 1136-1142, 2009.

[42] D. J. Hong, I. K. Bae, I.-H. Jang, S. H. Jeong, H.-K. Kang, and K. Lee, "Epidemiology and characteristics of metallo- $\beta$-lactamaseproducing Pseudomonas aeruginosa," Journal of Infection and Chemotherapy, vol. 47, no. 2, pp. 81-97, 2015.

[43] Z. Julio, C. Gerardo, P. Carlos, and T. Musharaf, "The combineddisk boronic acid test as an accurate strategy for the detection of KPC carbapenemase in Central America," The Journal of Infection in Developing Countries, vol. 10, no. 3, pp. 298-303, 2016. 


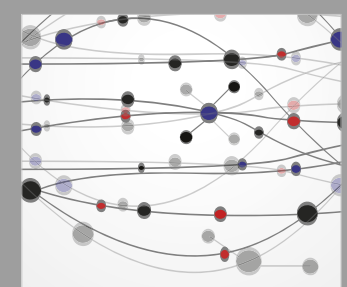

The Scientific World Journal
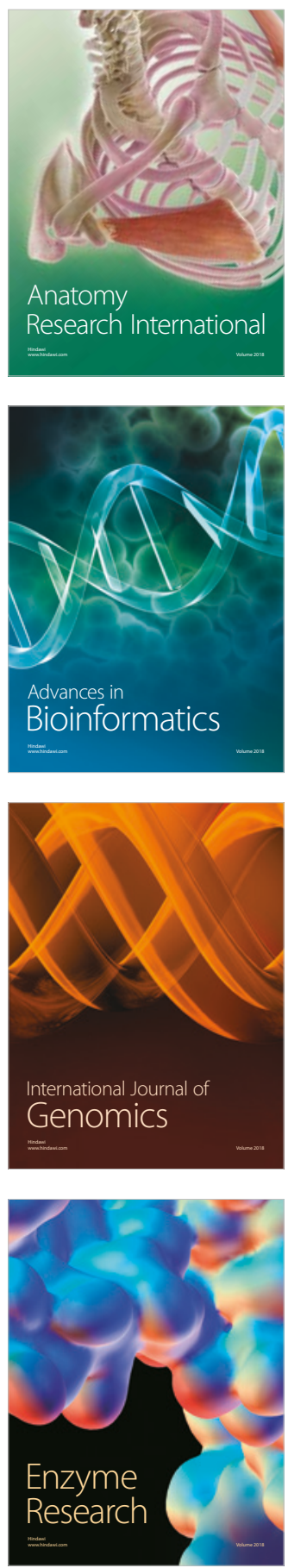
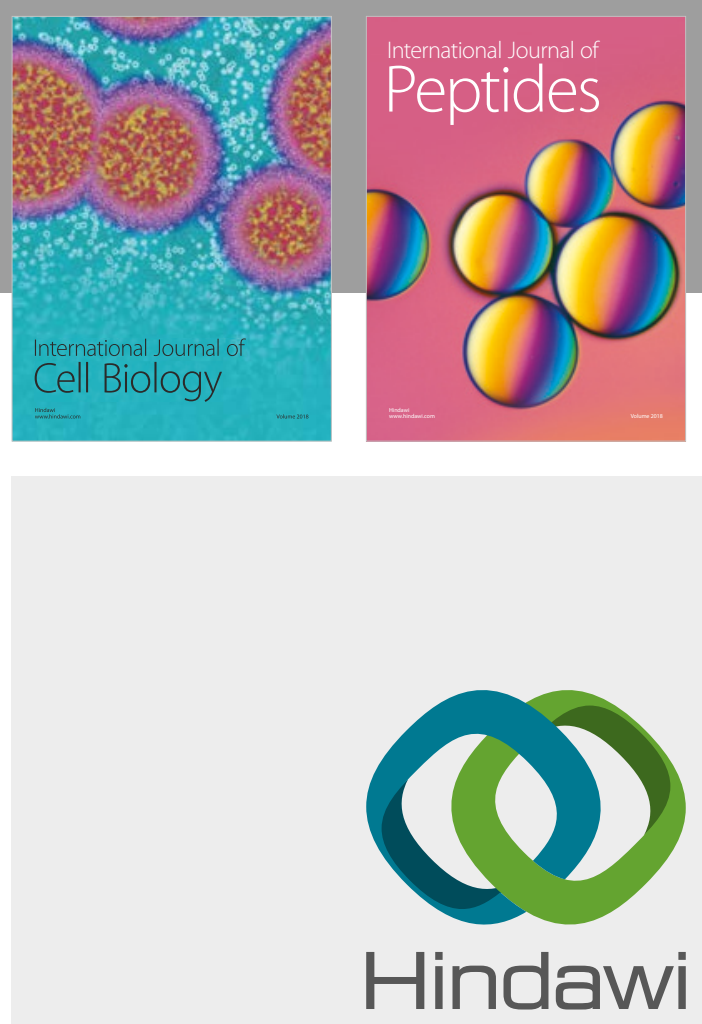

Submit your manuscripts at

www.hindawi.com
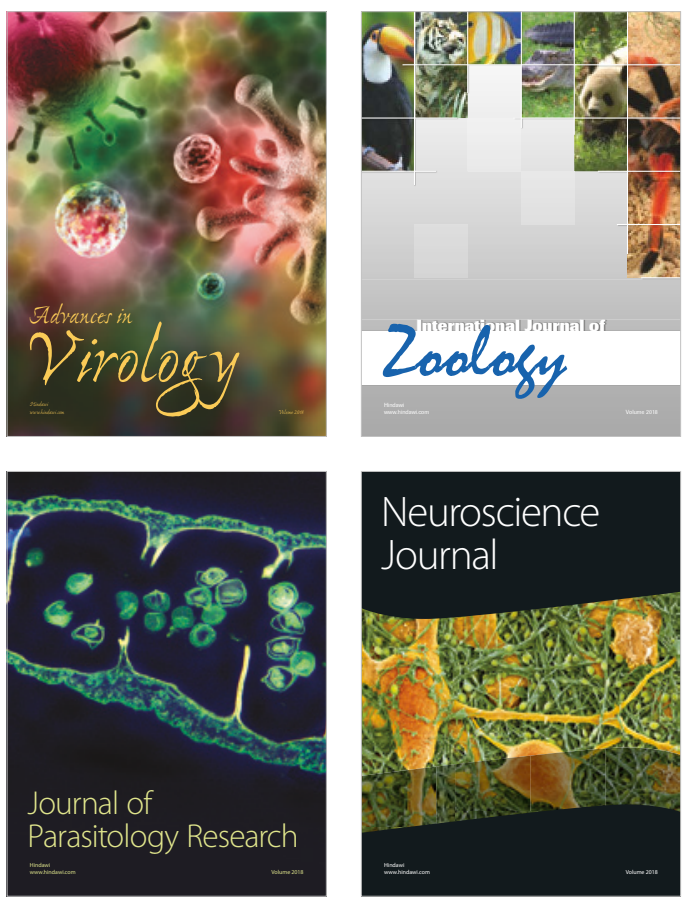
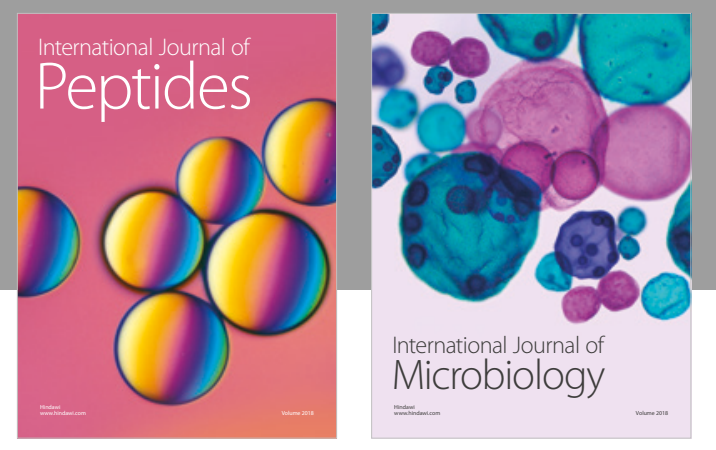

nternational Journal of Microbiology
Journal of
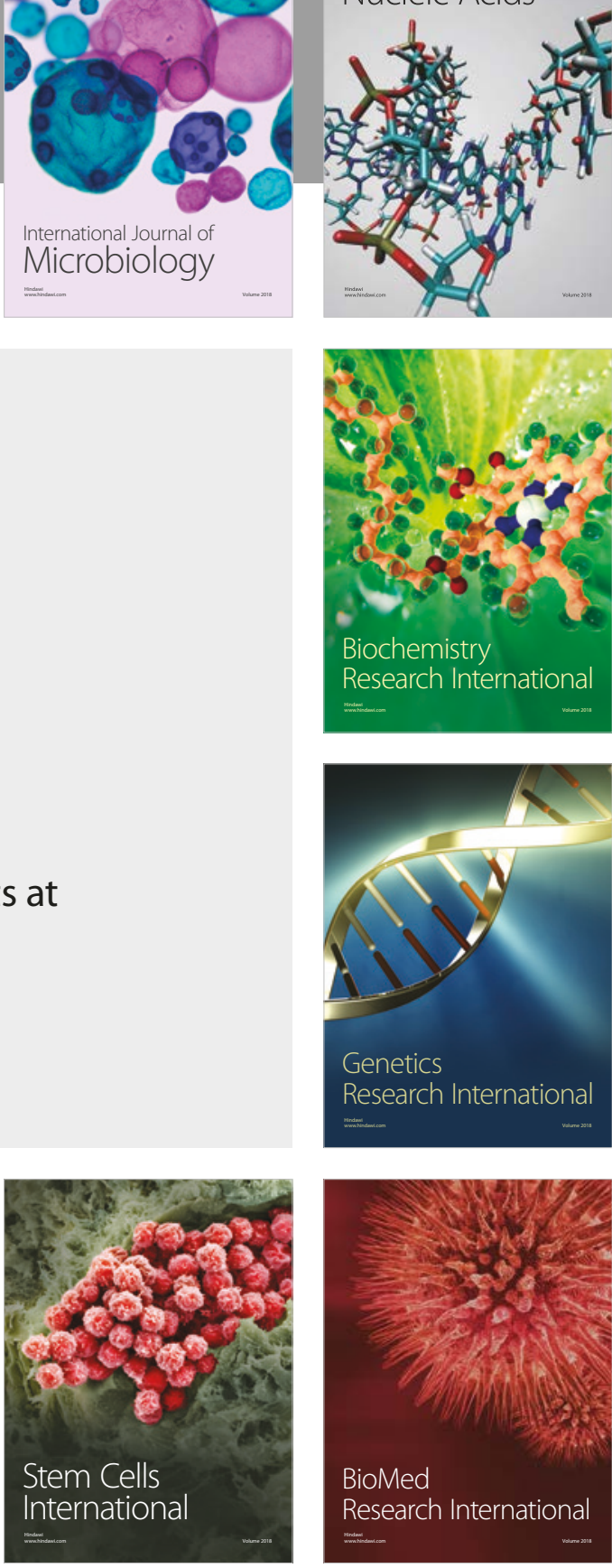
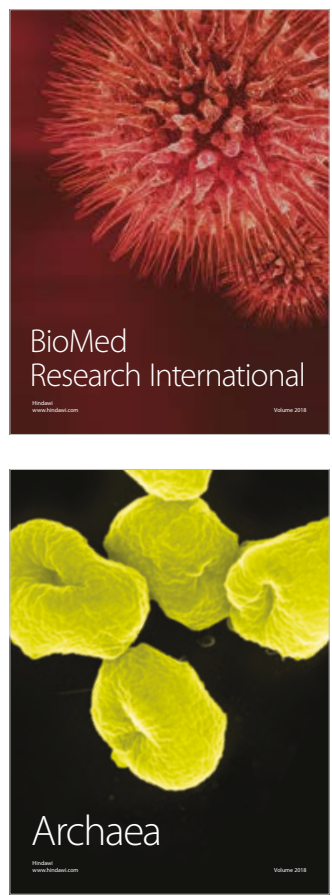